\title{
ANALISIS KEBERHASILAN INSEMINASI BUATAN PADA SAPI BALI DI KABUPATEN KARANGASEM
}

\author{
SWASTIKA, I G. L., N. W. T. INGGRIATI, DAN I G. S. ADI PUTRA \\ Program Studi Magister Ilmu Peternakan, Fakultas Peternakan, Universitas Udayana \\ e-mail: gusekapertanian@gmail.com
}

\begin{abstract}
ABSTRAK
Ternak sapi merupakan potensi terbesar yang dimiliki oleh Kabupaten Karangasem. Pada tahun 2016, populasi sapi di Kabupaten Karangasem mencapai 127.589 ekor (22,35\%) dari total populasi sapi di Bali. Penelitian ini bertujuan untuk mengetahui persepsi, motivasi, pengetahuan, sikap, dan keterampilan peternak terhadapinseminasi buatan (IB). Tujuan khusus dari penelitian ini adalah mengetahui persepsi, motivasi, pengetahuan, sikap, dan keterampilan tentang IB. Menganalisis tingkat keberhasilan IB. Menganalisis pengaruh pengetahuan, sikap dan keterampilan peternak terhadap persepsi peternak tentang IB. Pengaruh pengetahuan, sikap dan keterampilan peternak terhadap motivasi. Pengaruh persepsi, pengetahuan, sikap dan keterampilan peternak terhadap tingkat keberhasilan pelaksanaan IB. Desain penelitian adalah survei dengan menggunakan kuisioner di delapan kecamatan yang ada di Kabupaten Karangasem. Jumlah responden sebanyak 104 orang. Analisis dilakukan secara deskriptif dan analisis Path. Hasil penelitian menunjukkan bahwa peternak memiliki pengetahuan tentang IB tinggi, sikap tentang IB adalah positif, keterampilan mengetahui birahi tinggi, persepsi tentang IB positif, dan motivasi untuk melaksanaan IB kuat. Keberhasilan IB tinggi. Pengetahuan, sikap dan keterampilan peternak berpengaruh positif nyata terhadap persepsi peternak tentang IB. Pengetahuan, sikap dan keterampilan peternak berpengaruh positif nyata terhadap motivasi peternak tentang pelaksanaan IB. Pengetahuan, sikap dan keterampilan, persepsi dan motivasi peternak berpengaruh positif nyata terhadap tingkat keberhasilan pelaksanaan IB.
\end{abstract}

Kata kunci: inseminasi buatan, sapi bali, pengetahuan, sikap, persepsi

\section{THE ANALYSIS OF ARTIFICIAL INSEMINATION SUCCESS ON BALI CATTLE AT KARANGASEM REGENCY}

\begin{abstract}
is the most potential livestock sector of cattle at Karangasem because this regency has their biggest population in Bali. Their population in 2016 achieved 127.589 (22.35\%) from the total population in Bali. artificial insemination (AI) is one of the cattle development programs to support their population, quality, and production. This research aims at finding farmers perception, motivation, knowledge, attitude and technical skill on cattle AI. It aims at analyzing the influence of knowledge, attitude and technical skill of farmers on AI. These are used in order to motivate the AI program. This study was using a survey research with questionnaires for data collection at eight sub-districts of Karangasem regency with 104 selected respondents. Analysis of data was using path and descriptive analysis. The results showed that farmers with high knowledge, positive attitude, high technical skills, their perception to conduct AI program in highland were strong. It can be concluded that farmers' knowledge, attitude, and positive technical skills gave significant influences to the perception of farmers of AI. The level of AI implementation is categorized success at Karangasem regency.
\end{abstract}

Keywords: artificial insemination (AI), bali cattle, knowledge, attitude, perception

\section{PENDAHULUAN}

Pertambahan jumlah penduduk, meningkatnya kesejahteraan dan pendidikan masyarakat Indonesia, telah mendorong semakin meningkatnya permintaan akan produk peternakan yang berasal dari daging sapi.
Menurut data Direktorat Jenderal Peternakan dan Kesehatan Hewan (2016), sebanyak 25,4\% kebutuhan daging nasional dipenuhi dari daging sapi. Namun disayangkan $35 \%$ diantaranya berasal dari impor luar negeri, ini berarti populasi sapi belum mampu memenuhi kebutuhan daging nasional. 
Ternak sapi merupakan potensi terbesar yang dimiliki Kabupaten Karangasem pada sub sektor peternakan, bahkan populasinya terbanyak di Bali. Pada tahun 2016, populasi sapi di Kabupaten Karangasem mencapai 127.589 ekor $(22,35 \%)$ dari total populasi sapi di Bali (Dinas Peternakan, Kelautan dan Perikanan Kabupaten Karangasem, 2016). Salah satu program yang dikembangkan untuk mendukung peningkatan populasi, mutu dan produksi sapi adalah insiminasi buatan (IB) yaitu pemanfaatan semen pejantan unggul untuk diinseminasikan kepada betina produktif sehingga diperoleh keturunan yang berkualitas lebih baik. IB merupakan salah satu teknologi dalam reproduksi ternak yang memiliki manfaat dalam mempercepat peningkatan mutu genetik ternak, mencegah penyebaran penyakit reproduksi yang ditularkan melalui perkawinan alam, meningkatkan efisiensi penggunaan pejantan unggul, serta menurunkan/ menghilangkan biaya investasi pengadaan dan pemeliharaan ternak pejantan (Sugiarti dan Siregar,1999).

Keberhasilan dari program IB dapat dipengaruhi oleh peternak, inseminator dan pemerintah. Peternak berperan dalam menyiapkan ternak yang akan di IB, inseminator berperan dalam melaksanakan IB dan pemerintah berperan dalam menyediakan infrastruktur pelaksanaan IB. Dalam rancangan penelitian ini faktor penentu keberhasilan IB yang akan dilihat adalah karakteristik peternak, pengetahuan, motivasi, keterampilan, persepsi dan sikap peternak. Tingkat pengetahuan dan keterampilan peternak melakukan pengamatan terhadap timbulnya gejala birahi pada ternaknya akan mempengaruhi ketepatan dalam melaksanakan IB sehingga akan berpengaruh terhadap keberhasilan IB. Motivasi dan prilaku peternak juga mempengaruhi keberhasilan suatu teknologi, hasil penelitian oleh Okkyla et al. (2013) bahwa adanya hubungan positif antara motivasi dan prilaku peternak dalam pemanfaatan teknologi inseminasi buatan. Sikap peternak juga akan mempengaruhi keberhasilan suatu inovasi, semakin positif sikap peternak terhadap program IB maka tingkat keberhasilan IB akan semakin tinggi.

Partodiharjo (1982) menyatakan selain parameter peternak keberhasilan teknologi IB di lapangan dapat diukur dengan nilai service per conception atau S/C. Nilai S/C adalah jumlah IB yang dilakukan (service) untuk menghasilkan satu kebuntingan (conception).

Insiminasi buatan (IB) merupakan salah satu teknologi dalam reproduksi ternak yang memiliki manfaat dalam mempercepat peningkatan mutu genetik ternak, mencegah penyebaran penyakit reproduksi yang ditularkan melalui perkawinan alam, meningkatkan efisiensi penggunaan pejantan unggul, serta menurunkan/menghilangkan biaya investasi pengadaan dan pemeliharaan ternak pejantan IB (Sugeng,1997). Namun berhasil tidaknya pengembangan teknologi ditentukan oleh mau tidaknya petani mengadopsi teknologi yang dianjurkan sedang keputusan mengadopsi suatu teknologi banyak dipengaruhi sifat teknologi (Soekartawi,1998).

Oleh karena itu penelitian ini dilakukan untuk mengetahui tingkat keberhasilan IB, pengaruh karakteristik peternak, pengetahuan peternak, sikap peternak, keterampilan peternak, motivasi peternak dan persepsi peternak terhadap pelaksanaan IB di kabupaten Karangasem.

\section{METODE PENELITIAN}

\section{Desain Penelitian}

Penelitian ini merupakan penelitian survei yaitu dengan menggunakan kuesioner sebagai instrumen utama dalam pengumpulan data. Data yang diperoleh dari hasil tanggapan responden merupakan data kuantitatif dan kualitatif yang nantinya akan dianalisis untuk menguji model penelitian dan hipotesis menggunakan analisis Path.

\section{Lokasi dan Waktu Penelitian}

Penelitianinidilaksanakandi Kabupaten Karangasem pada peternak sapi bali yang pernah melakukan IB yaitu pada bulan Agustus tahun 2016. Lokasi penelitian ditentukan dengan metode purposif yaitu penentuan daerah yang didasarkan pada pertimbangan tertentu (Sujana, 1992). Dasar pertimbangan yang digunakan untuk memilih lokasi penelitian adalah Kabupaten Karangasem memiliki populasi sapi yang tertinggi yaitu 22,35\% dibandingkan kabupaten lain di Bali. Lokasi penelitian sudah dikenal oleh peneliti sehingga memudahkan dalam pengambilan data dan belum ada penelitian mengenai tingkat penerapan teknologi IB di lokasi penelitian ini sebelumnya.

\section{Sampel Penelitian}

Populasi dalam penelitian ini adalah peternak sapi bali yang pernah melakukan IB pada tahun 2015 dan berada di delapan Kecamatan di Kabupaten Karangasem yang berjumlah 3.988 peternak dengan sebaran seperti Tabel 1.

Teknik pengambilan sampel dimasing-masing kecamatan menggunakan metode kuota, dengan mengundi peternak yang pernah melakukan IB ditiap kecamatan. Agar jumlah responden dari masing-masing kecamatan jumlahnya sama maka jumlah responden yang diambil ditetapkan menjadi 104 sehingga setiap kecamatan jumlah respondennya 13peternak diambil secara acak. 
Tabel 1. Peternak yang melaksanakan Program IB di kabupaten Karangasem

\begin{tabular}{lc}
\hline \multicolumn{1}{c}{ Kecamatan } & Jumlah Peternak \\
\hline Sidemen & 480 \\
Abang & 476 \\
Selat & 490 \\
Kubu & 512 \\
Manggis & 467 \\
Rendang & 537 \\
Bebandem & 499 \\
Karangasem & 527 \\
Jumlah & 3988 \\
\hline
\end{tabular}

*Dinas Peternakan, Kelautan dan Perikanan Kabupaten Karangasem 2016

\section{Jenis, Sumber dan Pengumpulan Data}

Jenis data yang digunakan dalam penelitian ini adalah data primer dan sekunder. Data primer adalah data yang belum pernah diolah oleh pihak tertentu untuk suatu kepentingan. Data primer dalam penelitian ini bersumber dari sumber primer atau pihak pertama yang memiliki suatu data (Abdillah dan Jogiyanto, 2015). Pengumpulan data primer dilakukan dengan empat cara yaitu wawancara langsung, wawancara mendalam, observasi dan dokumentasi.

Data sekunder merupakan data yang telah diolah, disimpan dan disajikan dalam bentuk tertentu seperti data gambaran umum Kabupaten Karangasem dan populasi sapi Bali. Data sekunder diperoleh dari pihak kedua yaitu Dinas Peternakan, Kelautan dan Perikanan Kabupaten Karangasem.

\section{Pengukuran Variabel}

Variabel pengetahuan $\left(\mathrm{X}_{1}\right)$, sikap $\left(\mathrm{X}_{2}\right)$, Keterampilan $\left(\mathrm{X}_{3}\right)$, motivasi $\left(\mathrm{Y}_{1}\right)$, persepsi ( $\left.\mathrm{Y}_{2}\right)$, dan keberhasilan IB $\left(\mathrm{Y}_{3}\right)$ ditabulasi dan diukur seluruh indikator dari variabel penelitian menggunakan skala berjenjang lima $(1,2,3,4$, dan 5). Variabel yang sudah diberikan skor diklasifikasikan menjadi lima kategori yaitu sangat tinggi, tinggi, sedang, rendah, dan sangat rendah atau sangat baik, baik, sedang, buruk dan sangat buruk. Untuk pernyataan positif, respon sangat tinggi dan sangat baik diberi skor lima, sedangkan respon sangat rendah dan sangat buruk diberi skor satu. Demikian juga sebaliknya, untuk pernyataan negatif, respon sangat rendah dan sangat buruk diberi skor lima, sedangkan respon sangat tinggi dan sangat baik diberi skor satu (Singarimbun dan Effendi, 2006).

\section{Analisis Data}

Analisis data dalam penelitian ini menggunakan statistika deskriptif dan statistika inferensia. Statistika deskriptif sebagai metode yang berkaitan dengan pengumpulan, penyajian dan peringkasan suatu gugus data sehingga memberikan informasi yang berguna. Statistika deskriptif disajikan dalam bentuk frekuensi, distribusi frekuensi, persentase dan rataan skor. Statistika inferensia digunakan untuk menjelaskan besar hubungan antara variabel bebas dengan variabel terikat dan digunakan untukmenguji kebenaran hipotesis dari suatu penelitian untuk mencapai tujuan penelitian. Teknik analisis data yang digunakan dalam penelitian ini adalah analisis Path.

\section{HASIL DAN PEMBAHASAN}

\section{Evaluasi Deskriptif}

Hasil penelitian menunjukan bahwa $71,34 \%$ peternak sapi bali memiliki pengetahuan yang tinggi (Tabel 2). Tingkat pengetahuan peternak yang baik disebabkan karena tingkat pendidikan peternak yang menerima inovasi IB sebagian besar adalah SMA/ SMK sesuai dengan Soekartawi (1988) bahwa mereka yang berpendidikan lebih tinggi relatif lebih cepat melaksanakan adopsi.

Tabel 2. Sebaran peternak plasma berdasarkan variabel penelitian

\begin{tabular}{lcccc}
\hline \multicolumn{1}{c}{ Variabel } & $\begin{array}{c}\text { Pencapaian } \\
\text { skor* }\end{array}$ & $\begin{array}{c}\text { Persentase } \\
(\%)^{* *}\end{array}$ & Rataan Skor & Kategori \\
\hline Pengetahuan & $>68-84$ & 71,34 & 3,50 & Tinggi \\
Sikap & $>68-84$ & 73,65 & 3,64 & Positif \\
Ketemapilan & $>68-84$ & 76,15 & 3,89 & Tinggi \\
Persepsi & $>68-84$ & 74,03 & 3,47 & Positif \\
Motivasi & $>68-84$ & 72,88 & 3,97 & Kuat \\
Keberhasilan IB & $>68-84$ & 74,55 & 3,68 & Tinggi \\
\hline
\end{tabular}

Keterangan:

* Pencapaian skor: 20-36 : Sangat rendah/Sangat buruk

$>36-52 \quad:$ Rendah/Buruk

$>52-68 \quad:$ Cukup/Sedang

$>68-84 \quad:$ Tinggi/Baik

>84-100 : Sangat tinggi/Sangat baik

**Persentase peternak plasma (total responden $=104$ orang)

Selain itu, 73,65\% peternak sapi bali memiliki sikap yang positif. Sikap positif ditunjukkan dengan antusiasnya peternak sapi jika diberikan masukan atau saran terkait IB. Sebagian besar peternak memiliki keterampilan yang tinggi mengenai penanganan sapi yang dipeliharanya dan pengenalan ciri-ciri birahi pada sapi yang dipeliharanya 76,15\%. Keterampilan yang tinggi akan meningkatkan keberhasilan IB di Kabupaten Karangasem. Persepsi peternak sapi bali tentang IB tergolong positif $74,03 \%$. Motivasi peternak untuk melaksanakan IB tergolong tinggi $72,88 \%$. Motivasi yang tinggi mengindikasikan niat peternak sapi bali selalu bekerja dan berprestasi lebih baik agar cepat mencapai kebutuhan dan harapannya.

Pada Tabel 2, 74,55\% Keberhasilan IB di Kabupetn Karangasem tergolong tinggi karena peternak sapi bali memiliki pengetahuan dan keterampilan yang tinggi terhadap cara penangan sapi yang birahi dan keterampilan mengetahui ciri-ciri birahi pada sapi yang dipeliharanya. Tingkat keberhasilan IB di Kabupaten 
Karangasem dapat dilihat dari nilai Servis per Conception $(\mathrm{S} / \mathrm{C})$ atau jumlah pelayanan inseminasi yang dibutuhkan oleh seekor betina sampai terjadinya kebuntingan atau konsepsi pada tahun 2013 sebesar 1,36 kali, tahun 2014 sebesar 1,35 kali, tahun 2015 sebesar 1,33 kali dan 2016 sebesar 1,26 kali. Toelihere (1993) menyatakan bahwa nilai S/C yang normal berkisar antara 1,6-2,0.

\section{Analisis Model Persamaan Struktural}

Berdasarkan hasil perhitungan koefisien regresi (regression weight) yang dapat dilihat pada Tabel 3 dapat dibuat tabel output seperti disajikan dalam tabel berikut:

Tabel 3. Regression weights: (Group number 1 - Default model)

\begin{tabular}{|c|c|c|c|c|c|c|c|c|}
\hline & & & $\begin{array}{c}\text { Std. } \\
\text { Estimate }\end{array}$ & Estimate & S.E. & C.R. & $P$ & Label \\
\hline Y1 & $<---$ & $\mathrm{X} 1$ & ,410 & ,328 & ,036 & 9,129 & $* * *$ & Signifikan \\
\hline Y2 & $<--$ & $\mathrm{X} 2$ & ,882 & 380 & ,012 & 32,614 & $* * *$ & Signifikan \\
\hline Y3 & $<---$ & $\mathrm{X} 2$ & ,862 & ,835 & ,010 & 82,722 & $* * *$ & Signifikan \\
\hline Y2 & $<--$ & $\mathrm{X} 1$ & 201 & 220 & ,030 & 7,440 & $* * *$ & Signifikan \\
\hline Y1 & $<--$ & X3 & ,459 & ,384 & ,038 & 10,206 & $* * *$ & Signifikan \\
\hline Y2 & $<---$ & $\mathrm{x} 3$ & 327 & 375 & ,031 & 12,097 & $* * *$ & Signifikan \\
\hline Y1 & $<---$ & $x 2$ & ,643 & 202 & ,014 & 14,301 & $* * *$ & Signifikan \\
\hline Y3 & $<---$ & $\mathrm{X} 1$ & ,436 & 1,073 & ,026 & 41,852 & $* * *$ & Signifikan \\
\hline Y3 & $<--$ & X3 & 234 & ,603 & ,027 & 22,484 & $* * *$ & Signifikan \\
\hline
\end{tabular}

Pada Tabel 3 terlihat pengaruh variabel pengetahuan peternak terhadap persepsi peternak tentang IB memiliki standardized estimate (regression weight) sebesar 0,410 dengan $\mathrm{Cr}$ (Critical ratio = identik dengan nilai t-hitung) sebesar 9,129 pada probability 0,000. Nilai CR 9,129 > 2,000 dan Probability $=0,000<0,05$ menunjukkan bahwa pengaruh variabel pengetahuan peternak tentang IB terhadap persepsi peternak tentang IB adalah positif nyata.

Hasil penelitian menunjukkan pengetahuan peternak tentang IB berpengaruh signifikan terhadap persepsi tentang IB. Penelitian ini menunjukkan pengetahuan seseorang akan mempengaruhi persepsi seseorang untuk menerima atau tidak sebuah inovasi, sesui dengan pendapat Walgito (2003), persepsi merupakan suatu proses yang diawali oleh penginderaan yaitu suatu proses diterimanya stimulus oleh individu, melalui alat reseptornya, namun proses tersebut tidak berhenti sampai disitu saja, selanjutnya stimulus diteruskan ke pusat susunan saraf yaitu otak dan terjadilah proses psikologis sehingga individu menyadari apa yang dilihat, didengar dan sebagainya.

Hasil penelitian menunjukkan sikap berpengaruh signifikan terhadap persepsi peternak tentang IB. Sikap adalah suatu bentuk pernyataan evaluatif oleh seseorang terhadap suatu objek (Siagian, 1988). Semakin baik sikap seseorang terhadap suatu teknologi maka akan berpengaruh terhadap persepsinya, sesuai dengan pernyataan Donnelly (1996) bahwa sikap adalah determinan prilaku, sebab sikap berkaitan dengan persepsi, kepribadian dan motivasi.

Berdasarkan hasil analisis keterampilan peternak tentang IB berpengaruh signifikan terhadap persepsi peternak tentang IB. Keterampilan peternak tentang IB akan mempengaruhi tingkat persepsi peternak untuk menerima inovasi tersebut, sesuai dengan pernyataan Mardikanto (1993), bahwa ketereampilan peternak terhadap suatu usaha/inovasi, akan berpengaruh terhadap prilaku peternak tersebut menjalankan usahanya. Berdasarkan pengertian tersebut, maka dapat dinyatakan bahwa peningkatan keterampilan peternak sapi bali tentang IB akan meningkatkan persepsi peternak.

Berdasarkan hasil analisis pengetahuan peternak tentang IB berpengaruh signifikan terhadap motivasi peternak terhadap pelaksanaan IB. Tingkat pengetahuan peternak tentang IB menurut hasil penelitian menunjukkan positif. Pengetahuan yang baik akan meningkatkan motivasi seseorang untuk melaksanakan inovasi yang mampu meningkatkan pendapatannya, sesuai dengan pernyataan Green (1980), bahwa peningkatan pengetahuan akan menyebabkan perubahan perilaku, pengetahuan sangat penting diberikan sebelum individu melakukan suatu tindakan, tindakan akan sesuai dengan pengetahuan apabila individu menerima isyarat yang cukup kuat untuk memotivasi bertindak sesuai dengan pengetahuannya.

Sikap merupakan merupakan reaksi atau respon yang masih tertutup dari seorang terhadap suatu stimulus atau objek. Sikap juga merupakan kesiapan atau kesediaan untuk bertindak dan juga merupakan pelaksanaan motif tertentu (Notoatmojo 2005). Hasil analisis statistik menunjukkan sikap peternak tentang IB berpengaruh signifikan terhadap motivasi peternak terhadap pelaksanaan IB, artinya semakin baik sikap peternak tentang IB maka semakin tinggi motivasi peternak untuk melaksanakan IB.

Hasil analisis menunjukkan bahwa keterampilan peternak berpengaruh signifikan terhadap motivasi peternak tentang pelaksanaan IB, artinya semakin tinggi keterampilan peternak maka akan meningkatkan motivasi peternak, jika peternak terampil dalam melihat sapi betina yang dipeliharanya birahi, peternak terampil dalam menangani sapi sebelum dan sesudah di IB, kebuntingan pasti akan terjadi dan pada saatnya akan melahirkan pedet yang sehat, dengan bobot badan yang tinggi. Hasil yang baik akan meningkatkan motivasi peternak untuk terus menggunakan teknologi IB dalam mengawinkan sapi yang dipeliharanya.

Berdasarkan hasil penelitian pengetahuan peternak berpengaruh signifikan terhadap keberhasilan IB, 
seperti pengetahuan tanda-tanda birahi pada sapi bali, pengetahuan tentang hasil dan kualitas pedet yang dihasilkan oleh sapi yang di IB, akan menyebabkan meningkatnya peternak untuk mengadopsi IB, sehingga tingkat keberhasilan Pogram IB akan meningkat. Semakin tinggi pengetahuan peternak tentang suatu inovasi maka akan meningkatkan keberhasilan inovasi tersebut.

Pengaruh variabel sikap pternak terhadap tingkat keberhasilan pelaksanaan IB (Tabel 3) memiliki standardized estimate (regression weight) sebesar o,862 dengan $\mathrm{Cr}$ (Critical ratio = identik dengan nilai t-hitung) sebesar 82,722 pada probability 0,000. Nilai CR 82,722 > 2,000 dan probability $=0,000<0,05$ menunjukkan bahwa pengaruh variabel sikap peternak terhadap tingkat keberhasilan pelaksanaan IB adalah positif nyata. Sikap responden secara keseluruhan terhadap IB tergolong positif, kondisi tersebut yang membuat sikap peternak berpengaruh signifikan terhadap keberhasilan pelaksanaan IB di Kabupaten Karangasem. Sikap peternak yang positif terhadap IB akan menimbulkan keyakinan yang kuat jika teknologi IB dilakukan oleh peternak sapi bali dengan baik dan benar akan dapat meningkatkan keberhasilan IB.

Pengaruh variabel keterampilan peternak terhadap keberhasilan pelaksanaan IB (Tabel 3) memiliki standardized estimate (regression weight) sebesar o,234, dengan $\mathrm{Cr}$ (Critical ratio = identik dengan nilai t-hitung) sebesar 22,484 pada probability 0,000. Nilai CR 22,484 $>$ 2,000 dan probability $=0,000<0,05$ menunjukkan bahwa pengaruh variabel keterampilan peternak tentang IB terhadap keberhasilan IB adalah positif nyata. Berdasarkan hasil penelitian menunjukkan keterampilan peternak berpengaruh siginifikan terhadap tingkat keberhasilan IB, kondisi tersebut berarti semakin tinggi keterampilan peternak tentang IB maka akan semakin meningkatkan keberhasilan IB di Kabupaten Karangasem.

\section{SIMPULAN}

Dapat disimpulkan bahwa (1). Pengetahuan peternak tentang IBadalah tinggi, sikap peternak tentang IB adalah tergolong positif, keterampilan peternak tentang IB adalah tinggi, persepsi peternak tentang IB adalah positif, dan motivasi peternak untuk melaksanaan IB adalah kuat. (2). Keberhasilan IB pada sapi Bali di Kabupaten Karangasem tergolong tinggi. (3). Pengetahuan, sikap dan keterampilan peternak berpengaruh positif terhadap persepsi, motivasi peternak dan tingkat keberhasilan pelaksanaan IB.

\section{UCAPAN TERIMA KASIH}

Pada kesempatan ini penulis mengucapkan terima kasih peternak sapi bali di Kabupaten Karangasem yang telah meluangkan waktunya untuk diwawancarai, sehingga penelitian dan penulisan artikel ilmiah ini dapat terlaksana.

\section{DAFTAR PUSTAKA}

Dinas Peternakan Kelautan dan Perikanan Kabupaten Karangasem. 2016. Statistik Peternakan, Perikanan dan Kelauatan Kabupaten Karangasem. Denpasar: Dinas Peternakan, Kelauatan dan Perikanan Kabupaten Karangasem.

Direktorat Jenderal Peternakan dan Kesehatan Hewan. 2016. Statistik Peternakan 2016. Jakarta: Direktorat Jendral Peternakan dan Kesehatan Hewan.

Donnelly, G.I, 1996. Organisasi, Perilaku, Struktur, Proses. Jakarta: Bina Aksara.

Green, L. 1980. Precede-Procced framework. Columbia; My fieldPublisihing Company.

Mardikanto, T. 1993. Penyuluhan Pembangunan Pertanian. Surakarta: Sebelas Maret University Press.

Okkyla. 2013. Perilaku Organisasi. Jilid I. Jakarta: PT Indeks Kelompok Garmedia.

Partodiharjo, S. 1982. Ilmu Reproduksi Hewan. Mutiara. Jakarta.

Siagian, S. P. 1988. Teori dan Praktek Kepemimpinan. Jakarta : Bina Aksara.

Singarimbun, M. dan Effendi, S. 2006. Metode Penelitian Survai. LP3ES, Jakarta.

Soekartawi, 1988. Prinsip Dasar Komunikasi Pertanian. Universitas Indonesia, Jakarta.

Sugiarti dan Siregar. 1999. Dampak Pelaksanaan IB (IB) terhadap Peningkatan Pendapatan Peternak Sapi Perah di Daerah Jawa Barat. Jurnal Ilmu Ternak dan Veteriner Vol 4 (1): 3-5. Bogor.

Sujana, 1992. Metode Statistika edisi kelima, Tarsito, Bandung.

Toelihere, M. R. 1993. Fisiologi Reproduksi pada Ternak. Penerbit Angkasa. Bandung.

Walgito. 2003. Pengantar Psikologi Umum. Yogyakarta: Andi Offset 